\title{
Comportamento do Consumidor no Turismo: o turista estrangeiro em Florianópolis - Santa Catarina, Brasil
}

\author{
Consumer Behaviour at Tourism: the foreign tourist at \\ Florianópolis -Santa Catarina, Brazil
}

\author{
Luís Moretto Neto ${ }^{1}$ \\ Valentina Gomes Haensel Schmitt ${ }^{2}$
}

\begin{abstract}
Resumo
O presente estudo tem por objetivo analisar o comportamento de consumo do turista estrangeiro na cidade de Florianópolis, no período compreendido entre os meses de maio a junho de 2006, a partir da avaliação das determinantes individuais de consumo e dos elementos que integram o produto turístico disponível. Fundamentados em base teórica que possibilita análise do comportamento do consumidor e a partir de inferências realizadas no mercado turístico, particularmente, através de estudo de caso. A população estudada, 204 indivíduos, representando a demanda de turistas estrangeiros que visitaram, em 2006, a cidade de Florianópolis. As constatações e proposições relacionadas ao comportamento do turista estrangeiro, notadamente, no espaço e período estudados, enquanto consumidor, permitem realizar inferências e definir ações estratégicas de mercado.
\end{abstract}

Palavras-chave: comportamento do consumidor; turismo; marketing.

\begin{abstract}
The present study had as its objective to analyze the foreign tourist's consumer behavior in Florianopolis, between the months of May and June of 2006. The utilized variables for analyzes were: the foreign tourist, the consumer behavior characteristics, the individual determinants of the consumer behavior and the elements of the product of tourism. The studied population represents the foreign tourist demand in the city of Florianopolis, in the year of 2006, the sample group had a total of 204 participants. Both, notices and propositions, especially, the space and the studied time, while consumer, allow to achieve inferences and to define strategic market actions.
\end{abstract}

Keywords: consumer behavior; tourism; marketing.

\section{Introdução}

Florianópolis recebe cerca de seiscentos mil visitantes ao ano, incluindo-se estrangeiros, brasileiros de outros estados e catarinenses de outras cidades. O fluxo internacional, conforme

\footnotetext{
${ }^{1}$ Graduado em Administração pela UFSC. Mestre em Geografia pela UFSC. Doutor em Engenharia de Produção e Sistemas pela UFSC. E-mail: moretto@cse.ufsc.br

${ }^{2}$ Bacharel e Mestre em Administração pela UFSC. Doutoranda em Administração pela FGV-RJ. E-mail: valentinaschmitt@hotmail.com
} 
a SANTUR - Órgão Oficial de Turismo do Governo do Estado de Santa Catarina-, é da ordem de vinte por cento do mercado emissivo tido como amplo e promissor (SANTUR , 2005).

Mesmo diante da relevância da atividade turística para a economia municipal, principalmente durante a estação verão, não existem dados oficiais consolidados sobre a atividade durante a baixa temporada, ou pesquisas detalhadas sobre o comportamento do consumidor turista.

A SANTUR, em parceria com a Prefeitura de Florianópolis, realiza anualmente Pesquisa Mercadológica da Demanda Turística, seguindo padrões da Organização Mundial do Turismo (OMT). Tais levantamentos permitem colher informações sobre características da população que visita Florianópolis no período e visam nortear ações dos setores públicos e privados na busca de incentivos para a atividade, bem como à realização de investimentos em infraestrutura, promoção, construção de equipamentos e elaboração de planos estratégicos, voltados ao incremento quantitativo e qualitativo dos fluxos turísticos. Todavia, percebe-se a carência de precisão e grau de detalhamento das informações obtidas além da ausência de diferenciação no perfil de comportamento entre turistas brasileiros e estrangeiros. Todos são avaliados de forma conjunta havendo dificuldade de utilização adequada das informações que visam o direcionamento de ações e recursos segmentados por pólos emissivos.

Devido à carência de pesquisas e referencial teórico sobre comportamento de consumo no turismo brasileiro, julgou-se adequada a realização de pesquisa sobre o comportamento do turista estrangeiro em Florianópolis, visando o enriquecimento no campo de estudos em gestão de empreendimentos turísticos, bem como a geração de subsídios para a gestão e organização do turismo no município. O estudo teve por objetivo principal analisar o comportamento de consumo do turista estrangeiro Florianópolis, no período compreendido entre os meses de maio a junho de 2006, no saguão de embarque do Aeroporto Internacional Hercílio Luz. A metodologia empregada foi a de estudo de caso, a partir de uma amostra de 204 turistas estrangeiros, escolhidos de forma aleatória. A coleta de dados foi realizada por intermédio de instrumento estruturado e não disfarçado.

A tabulação ocorreu com o uso do programa de computador SPHINX - ferramenta de pesquisa elaborada pela SPHINX Brasil, o qual possibilita análise quantitativa e de conteúdo, técnicas empregadas neste trabalho. 
O presente artigo encontra-se estruturado na apresentação dos pressupostos teóricos, aspectos metodológicos, apresentação e análise dos dados, conclusões e principais referências bibliográficas utilizadas no seu desenvolvimento.

\section{Pressupostos Teóricos}

Em 1910 o economista austríaco Herman von Schullern teria sido a primeira pessoa a conceituar a atividade turística a partir de uma perspectiva empresarial e econômica (BENI, 2003: 34). Na definição apresentada o turismo seria “... a soma das operações, especialmente as de natureza econômica, diretamente relacionadas com a entrada, permanência e deslocamento de estrangeiros para dentro e para fora de um país, cidade ou região". Tal definição teria sido o marco inicial para a delimitação e compreensão da atividade turística. No entanto, estaria restrita aos conceitos de deslocamento e permanência, excluindo dessa forma a natureza do deslocamento (ex: lazer, negócios).

Nas sociedades pós-industriais, argumenta Trigo (1996), o turismo juntamente com o lazer, a cultura, as artes, o esporte e a preocupação com a qualidade de vida, desenvolveu-se a cada ano, ganhando sempre espaço nos meios de comunicação, nas atividades internacionais, no interesse e no cotidiano das pessoas. Assim, a atividade turística faz parte da sociedade “... ativa, questionada, mutável e multifacetada.” (TRIGO, 1996: 66). Na atividade turística, a diversidade cultural e a abertura às novas experiências fazem parte do cotidiano.

O turismo é um fenômeno eminentemente social e tem como elementos os turistas, os trabalhadores e o grupo estável receptor composto pela comunidade local (BENI, 2003). O turismo pode ser empregado para fins de desenvolvimento nacional e regional, nos campos social, cultural e no político. As atividades originadas fazem gerar efeitos sobre o meio ambiente, e o desenvolvimento do turismo está bastante relacionado com a transformação do território.

Sendo a atividade turística causadora de impactos, tanto socioeconômicos como ambientais, observa-se a necessidade de compreensão do sistema que esta abrange para a adequação de gestão. 
Segundo Bertalanfy (1973: 84) “Um sistema pode ser definido como um complexo de elementos em interação ${ }^{3 \%}$. Os sistemas podem ser classificados em abertos ou fechados, sendo abertos aqueles que tem interação com seu ambiente externo. Em ciências sociais a teoria dos sistemas serve de base para a compreensão do comportamento individual em diferentes ambientes que são expostos.

O sistema turístico é aberto e formado pela oferta e suas interfaces com a demanda. A atividade turística, enquanto sistema relaciona-se com os ambientes sociais, culturais, políticos, econômicos e com os ecossistemas e é dependente de seus subsistemas. Os sistemas turísticos para Boullón (1985: 32) são compostos de: demanda e oferta turística, processo de venda, produto turístico, planta e atrativos turísticos, infraestrutura, superestrutura e patrimônio turístico. O ponto de partida do funcionamento do sistema origina-se no encontro da oferta com a demanda através do processo de venda do produto turístico, que junto à infraestrutura formam a estrutura de produção do setor. A função da superestrutura do sistema turístico é o controle da eficiência deste, vigiando e controlando a inter-relação das partes. O sistema turístico recebe influências do ambiente externo é dependente dos subsistemas que o compõe e tem início nas interfaces ente oferta e demanda. A compreensão de sistemas em turismo decorre do entendimento dos fatores pelos quais esses são compostos e influenciados.

O produto turístico é composto de bens e serviços unidos por relações de interação e interdependência que o tornam extremamente complexo. A OMT classifica os componentes do produto turístico - incluindo bens e serviços - em duas categorias básicas: produtos específicos e não específicos (OMT, S/D).

Os produtos específicos são resultantes do somatório de dois grupos: produtos turísticos característicos e produtos turísticos conexos.

Os produtos turísticos característicos são aqueles dos quais, na maioria dos países, tenderiam a desaparecer caso não houvesse o turismo, e para os quais as informações estatísticas são consideradas possíveis de obtenção. Incluem-se os serviços de acomodação (hotéis e estabelecimentos de hospedagem, e segunda residência e acomodação por conta própria ou gratuita); Serviços de alimentos e bebidas; Serviços de transporte de passageiros (ferroviário,

\footnotetext{
3 “A interação significa que os elementos p estão em relações R, de modo que o comportamento de um elemento p em R é diferente de seu comportamento em uma relação R”” (BERTALANFFY, 1973) O comportamento das variáveis é alterado conforme a relação que são expostas.
} 
aquático, terrestre e aéreo), suporte de passageiros, equipamento de locação de transporte de passageiros, serviços de manutenção e reparo de transporte de passageiros; Agências de viagens, operadoras de turismo e guias turísticos; Serviços culturais; Serviços de recreação e entretenimento; Serviços diversos.

O produto turístico conexo é uma categoria residual que inclui aqueles produtos que foram identificados como específicos do turismo em um determinado país, mas por quais esses atributos não são considerados numa base mundial.

Os produtos não específicos são aqueles que os visitantes podem consumir, porém não respondem pela parcela mais importante demandante. Dentre os produtos não-específicos estão os bens de consumo que são considerados não-específicos da atividade por duas razões principais: 1. a diferença significante entre os bens adquiridos, tanto em nível como estrutura, pelos visitantes de acordo com o pais visitado, 2.a existência de limitações de fontes disponíveis para a aquisição de informações estatísticas. Os produtos não específicos, segundo a OMT, são considerados sem interesse significativo para análises do turismo.

Os produtos turísticos são classificados por Boullón (1985: 38) em complementares e substitutos. Complementares são os que podem ser consumidos juntamente com outros. Os substitutos são aqueles que podem ser consumidos em troca de outros.

A atividade turística, segundo Figuerola (1985) está composta de quatro grandes conjuntos de empresas ou entidades, classificadas segundo suas atividades ou função principal: empresas de serviço ao viajante no ponto de origem da viagem, empresas de transporte, empresas de atenção ao visitante que recebem o turista no destino, e entidades de fomento, controle e organização

O conjunto de elementos básicos que integram a categoria de equipamentos e ou do produto turístico pode ser dividido em quatro blocos distintos e interdependentes, quais sejam os da área de alimentação, hospedagem, lazer e outros serviços. Outros elementos - tais como infraestrutura e serviços indiretamente relacionados - podem ser acrescidos para agregar valor ao conjunto básico da recepção do turista no pólo receptivo.

Os serviços representam elementos constitutivos importantes no composto da oferta turística na medida em que possibilitam a vivência de experiências por parte dos seus usuáriosturistas. Uma de suas características é que a heterogeneidade da demanda faz com que as 
expectativas sejam tão diversificadas que tornam a apreciação e conseqüentemente, a sua avaliação final sujeita a diversas interpretações.

Pine e Gilmore (1999: 12) acreditam que a economia seguiu uma escala de progressão que teve as seguintes fases características nas relações de troca: 1. commodities, 2. bens, 3. serviços e 4. sensações. Na fase da economia em que as trocas são baseadas em sensações o cliente é o próprio produto, que busca a sua transformação. O serviço turístico consiste em parte de um processo de produção revestido de determinadas características sociais. Destacam-se as características dos elementos nas relações de contato, as relações entre trabalhadores, turistas e moradores. As interações na atividade turística podem ser caracterizadas como um "trabalho emocional” e os prazeres do turismo derivam de processos complexos de produção e consumo. O gerenciamento de produtos turísticos deve observar que os clientes não querem alternativas impostas, querem exatamente o que desejam (PINE et al, 1999: 90). Os clientes procuram valor, não simplesmente o serviço (COBRA, 2001: 21).

Devido à grande diferenciação entre o produto turístico com os demais tipos de produtos, há a necessidade da compreensão adequada de suas características, abrangência e forma de gerenciamento. Neste processo a análise do comportamento do consumidor é um dos instrumentos que facilita o processo de tomada de decisão.

O mercado-alvo de uma localidade é composto por: visitantes, moradores e trabalhadores, negócios e indústrias, e mercado de exportação (KOTLER, 1994: 25). O grupo de visitantes que compõe o foco central do mercado de consumo da atividade turística é constituído por indivíduos que viajam a lazer, negócios e ou por outros infinitos motivos.

A demanda total do produto turístico é composta pelas demandas potencial e real. As demandas potenciais são todas aquelas pessoas que de alguma forma sentem alguma motivação à prática turística. As demandas reais são somente aquelas pessoas que de fato praticam o turismo, os turistas, excursionistas e visitantes.

O turista, na concepção da OMT, é a pessoa que realiza viagens e estadas em lugares distintos de seu entorno habitual, por um período de tempo consecutivo inferior a um ano, com fins de lazer, negócios ou por outros motivos não relacionados ao exercício de alguma atividade remunerada no local visitado (OMT, S/D). 
Na avaliação de cada turista está à sobrevivência dos sistemas turísticos, acredita Petrocchi (2001: 235). “Países que dão ao turismo sua devida importância realizam estudos e pesquisas de mercado, numerosos e específicos para cada um dos mercados existentes. ”

No Brasil, ocorre o desenvolvimento de três tipos de pesquisas relacionadas ao consumo turístico, as de demanda turísticas, as Contas Satélites do Turismo e as pesquisas do trade internacional. As pesquisas de demanda turísticas têm por objetivo principal identificar o perfil do turista que freqüenta o destino e sua avaliação com relação aos elementos disponíveis na oferta frente ao utilizado. As Contas Satélites do Turismo de outra parte, em fase de implantação no território nacional, tem por objetivo central a medição dos impactos quantitativos e qualitativos da atividade turística no Produto Interno Bruto - PIB - das localidades - cidades, estados e países - receptores dos fluxos. As pesquisas do trade internacional desenvolvidas no Brasil têm por objetivo específico analisar o perfil dos fluxos estrangeiros que demandam ao país e o volume médio de gastos diário durante sua estada no território nacional.

Os mercados consumidores, de acordo com Kotler (2003:118), consistem de indivíduos e famílias (seus grupos de relação) que compram bens e serviços para consumo pessoal.

Para Blackwell (et al, 2000) as variáveis que afetam o comportamento de consumo são: recursos do consumidor, conhecimento, atitudes, motivação, personalidade. Swarbrooke (et al, 2002) acrescentam às variáveis anteriormente citadas a percepção.

Os recursos do consumidor são analisados em três categorias fundamentais: 1. econômica, 2. temporal e 3. cognitiva. Tais categorias apresentam duas limitações básicas de orçamento: o monetário e o uso do tempo. O recurso econômico é resultado das receitas dos turistas durante o período em que estão em seu ambiente cotidiano de trabalho. Estes representam a forma como o turista paga pelos bens e serviços adquiridos durante a sua estada no local visitado. A forma como o tempo é alocado, denominado estilo de tempo, refere-se a como os consumidores dedicam seu tempo livre para a realização de atividades. Os consumidores que tem a sua disposição informações adequadas e sabem como fazer uso das mesmas podem alcançar volume de bens e serviços para si, assemelhada aos que dispõem de um padrão superior de recursos econômicos ou mesmo de tempo. A essência da concorrência de mercado está na participação pelos gastos dos consumidores (GORDON, 2004: 43). 
Num âmbito geral, o conhecimento é considerado como a informação armazenada pelos indivíduos. O subconjunto de informação que apresenta relevância ao consumo e à compra é denominado conhecimento do consumidor. Há dois tipos básicos de conhecimento: declarativo e o de procedimento (ENGEL et al, 2000: 224). Do ponto de vista do marketing os autores afirmam que é interessante dividir o conhecimento em três outras categorias: de produto, de aquisição e de uso.

Os gostos e aversões dos consumidores são conhecidos por atitudes. O modo de ser dos consumidores espelha as suas atitudes. As atitudes podem variar ao longo de uma série de dimensões ou propriedades. As dimensões são a valência ${ }^{4}$, extremidade, resistência, persistência e confiança. De modo geral, atitudes e intenções são bons indicadores tanto para medidas longitudinais quanto transversais - preferencialmente antecedendo à ação. Atitudes e intenções não são estáticas, ao contrário, são alteradas diante de circunstâncias inesperadas ou influências situacionais (ENGEL et al, 2000: 507). Atitudes podem ser formadas tanto com o contato direto ou indireto do objeto de atitude. No entanto, essas são freqüentemente formadas como resultante do contato direto.

As motivações podem ser classificadas em duas categorias amplas, com base nos benefícios esperados da compra e uso: 1. necessidades utilitárias e 2. necessidades hedonistas/vivenciais. As necessidades utilitárias levam em consideração os atributos ou benefícios objetivos, funcionais, do produto. As necessidades hedonistas/vivenciais abrangem respostas, prazeres, fantasias e considerações estéticas subjetivas. As necessidades hedonistas e utilitárias, de modo freqüente são aliadas no processo de decisão de compra.

A personalidade pode adquirir inúmeros significados. No campo de estudo do comportamento do consumidor, a personalidade diz respeito às respostas consistentes aos estímulos ambientais (ENGEL et al, 200). A personalidade de um indivíduo proporciona experiências e comportamentos relacionados, ordenados e coerentes em uma situação de consumo. A personalidade é o padrão particular, único, de organização que torna um indivíduo diferente de todos os outros e proporciona consistência de respostas baseada em características psicológicas existentes internamente e que demonstram-se duradouras. Para aplicações de natureza mercadológica, a personalidade refere-se à comunicação dos atributos do produto e às percepções desses atributos recebidos pelos consumidores sobre marcas específicas.

\footnotetext{
4 “valência refere-se ao fato da atitude ser positiva, negativa ou neutra (ENGEL et al, 2000: 629)”
} 
Percepção é a criação de quadros do mundo, a apreensão da realidade que se dá pela formação de conceito através da comparação de atitudes e juízos. O estudo da percepção possibilita conhecer a visão de pessoas externas a um contexto em relação a este. A imagem é o elemento que serve para criar vínculo entre o público e o produto, através da relação de valor e potencial de satisfação das necessidades (SÁ, 2002:12). A imagem é a idéia que diferencia um produto dos demais.

Organizar um programa de promoção requer o conhecimento do consumidor para que se elabore um conjunto de objetivos e estratégias em relação ao visitante ao invés de trabalhar ao acaso (KOTLER, 1994: 176). O objetivo central do marketing é, portanto, o estabelecimento de um conjunto de significados que caracterizem o destino enquanto marca, e que o torne distinto o suficiente aos olhos do consumidor em relação aos concorrentes. Um conceito adquire força uma vez que há convergência, reconhecimento das características em diferenciados discursos que compõe a imagem percebida a respeito do local.

Swarbrooke e Horne (2002) destacam que a melhoria na qualidade e quantidade das pesquisas sobre o comportamento do consumidor em turismo pode ser um indicador de amadurecimento da atividade turística.

\section{Aspectos Metodológicos}

O método faz uso de abordagem predominantemente quantitativa incorporando, no entanto, características qualitativas, em face da natureza das variáveis do estudo. A análise quantitativa foi baseada no emprego de técnicas de estatística descritiva de dados, através das variáveis comportamentais, dos recursos, do conhecimento e das atitudes do consumidor. A abordagem qualitativa foi realizada a partir da análise das variáveis motivação, personalidade e percepção do consumidor em relação ao produto turístico - Florianópolis. O estudo teve como dimensão temporal o corte transversal. Sendo que, o mesmo foi resultado da aplicação de questionário estruturado, não disfarçado com questões fechadas e abertas, nos idiomas português, inglês e espanhol, que demandaram a cidade de Florianópolis, durante os meses de maio e junho de 2006, sendo que a coleta foi efetuada junto ao terminal aeroviário internacional de passageiros - Hercílio Luz. Além das técnicas de pesquisas já descritas deu-se a aplicação da observação participante através do registro de hábitos e costumes dos entrevistados, complementados por análises documentais, estatísticas e de conteúdo. 


\section{Apresentação e Análise dos Dados}

A apresentação e análise dos dados apresentam-se disposta em duas etapas: 1. quantitativa, 2. qualitativa.

Com relação ao elemento de maior representatividade no volume médio de gastos diários, a hospedagem demanda aporte de U\$ 106,70 - equivalente no período a $\mathrm{R} \$ 234,80$, sendo o pagamento em moeda corrente o mais utilizado pelos entrevistados, e dentre os usuários de cartão de crédito a bandeira VISA é a preferida.

Quanto à utilização do tempo a parcela do público que viaja ao menos duas vezes ao ano é maioria. Há a predominância de períodos de visitações de 4 a 7 dias (44,6\%). Paralelamente, existe a predominância de escolha pela visitação de outras cidades brasileiras (59,8\%).

Constatou-se que 56,4\% dos respondentes não haviam visitado Florianópolis anteriormente, e dentre os entrevistados somente 36,8\% já haviam visitado outra capital brasileira situada no litoral. A cidade do Rio de Janeiro foi apontada como a mais conhecida pelos estrangeiros $(50,4 \%)$.

Como fontes de informações utilizadas destacaram-se a internet e amigos e parentes respectivamente $44,6 \%$ e 38,2\%. Independentemente da nacionalidade, a página de pesquisa GOOGLE foi a mais citada como fonte de informações em turismo. As informações demandas, por ordem de importância, foram apontadas como características gerais, hospedagem, entretenimento, lazer, transporte e alimentação. Para 41,2\% dos entrevistados as informações de maior utilidade foram aquelas obtidas durante a viagem.

O estudo demonstrou que há a atitude positiva em relação à Florianópolis, sendo a média atribuída ao município foi de 8,15. Os atributos considerados de maior importância em uma cidade turística são os meios de hospedagem e a segurança, e quanto ao grau de satisfação destacaram-se os meios de hospedagem e o atendimento ofertado no município. Com relação a fidelização, cerca de 95,6\% do público entrevistado demonstrou interesse no retorno a Florianópolis e 98,5\% demonstram predisposição em indicar Florianópolis como destino turístico. 
A principal motivação para a visitação, no período analisado, foi a participação em eventos destacando-se o Iron Man. A visita a amigos e parentes surge como segunda opção mais respondida $(17,2 \%)$ e o descanso como terceiro fator motivador.

Resgatando a participação em eventos como fator de motivação mais respondido, verifica-se a relevância de um evento em especial: o Iron Man. O evento esportivo, de características internacionais, mostrou-se como motivação por parte de $18,1 \%$ do público entrevistado e 69,8\% daqueles que se deslocaram motivados pela participação em evento, na cidade de Florianópolis, durante o período de análise, que cabe ressaltar é de baixa temporada ${ }^{5}$.

O turista estrangeiro em Florianópolis viajou predominantemente acompanhado e 47,1\% dos entrevistados atuaram como decisores na escolha do destino.

Cerca de $75 \%$ do público encontrou dificuldades durante a sua estadia, com destaques para as relacionadas ao idioma, transporte e informações. A imagem predominante da cidade é a de praia e mar e os residentes como segundo fator -descrita de diversas formas como: alegre, gentil, receptiva.

O meio de transporte utilizado por 88,2\% dos entrevistados, para o ingresso no município foi o avião, e como meio de transporte interno as principais opções o automóvel alugado (27\%) e o transporte coletivo (26,5\%). A maioria dos usuários de serviços de táxi e transfer são hóspedes dos hotéis e estabelecimentos afins - como pousadas. Os principais meios de hospedagem utilizados foram hotéis (51\%) e pousadas (18,1\%). Para a realização de refeições a maioria utilizou como opção principal os restaurantes $(55,9 \%)$ e a segunda opção mais utilizada, por 37,7\% dos entrevistados, o preparo de refeições no local de hospedagem. As principais opções de entretenimento utilizadas foram a visitação de praias (30,4\%), realizações de passeios e caminhadas (23,5\%), participação de atividades do evento (21,6\%).

A pesquisa conseguiu com êxito obter respostas de entrevistados de 28 nacionalidades, de todos os continentes. Dentre os entrevistados 38,4\% eram de origem da Argentina, 24\% dos Estados Unidos, 8,3\% do Reino Unido, 2,9\% da Alemanha e 2,9\% Suíça. O gênero distribuído em $57,8 \%$ do sexo masculino e $42,2 \%$ do sexo feminino. A faixa etária média de 40 anos, apresentando variações de 16 a 85 anos. Dentre os entrevistados predominaram os solteiros (50\%) e casados (39,7\%). A escolaridade mínima de 73,3\% dos entrevistados grau superior completo e, dentre estes $27 \%$ possuem algum tipo de pós-graduação. A renda 
familiar média predominante é superior a U\$2.549,52, sendo a renda de maior freqüência superior a U\$3.186,89. Analisando a renda em relação à região de origem do turista, constatou-se que aqueles provenientes do Hemisfério Norte são os que apresentam renda superior, enquanto os níveis de renda inferiores são ocupados por turistas provenientes da América do Sul.

A análise qualitativa do estudo remeteu às seguintes constatações.

Para que o município possa de fato competir por uma maior participação no mercado turístico é de fundamental relevância que ocorra o incremento na oferta de equipamentos e serviços que possibilitem aos usuários - residentes e visitantes - maiores facilidades de consumo, como por exemplo, acessibilidade a caixas eletrônicos conveniados com a rede ATM asynchronous transfer mode. Constatou-se que há uma problemática em torno dos cartões bancários - de crédito, débito e saque - câmbio de moedas e traveller cheques que devem ser sanadas imediatamente. A facilitação do acesso ao dinheiro e formas de pagamento viabiliza a realização de gastos por parte dos turistas e, paralelamente, confere um maior grau de segurança - por não necessitar portar grandes quantias consigo.

Ao constatar que o turista que visita Florianópolis costuma visitar cidades vizinhas, visualizase a possibilidade de oferta de pacotes turísticos de visitação a outras localidades do Estado objetivando, então, ampliar a oferta de produtos e fidelizar o visitante ao ofertante.

Tomando por base o fato de a cidade do Rio de Janeiro ser amplamente citada entre os entrevistados - por já ter sido visitada -, acredita-se que a realização de campanhas promocionais de Florianópolis a partir dessa localidade seria uma opção de custo reduzido, com potencial de atração de públicos estrangeiros de diferentes nacionalidades e com prédisposição para a visitação.

Tendo a Internet como a principal fonte de informações a respeito da atividade turística, a maior dificuldade sentida pelos turistas é a barreira idiomática, aliada ao fato que o turista antes da realização da viagem busca informações generalistas a respeito do destino a ser visitado. Conclui-se que é fundamental a adequação das páginas de conteúdo turístico do município, seja com relação aos conteúdos ou mesmo quanto a forma de comunicaçãolinguística. Cabe ressaltar que em pesquisas realizadas na rede, fazendo uso do endereço www.google.com - a mais citada entre os entrevistados- contatou-se que as principais páginas

${ }^{5}$ Reforçando o potencial do segmento de eventos para a redução da sazonalidade 
do município, incluindo a da prefeitura, apresentam informações superficiais e somente no idioma português.

O estudo de atitude apresentou uma posição favorável para o turismo no município, que aliado ao fato de as indicações de amigos e parentes serem a segunda fonte de informação mais utilizada pelos entrevistados, demonstra um potencial favorável de prosperidade do turismo em Florianópolis. O estudo remete também à questão das informações e serviços de transporte no município que devem ser readequados.

Tendo o turismo de eventos como principal fator de motivação à visitação de Florianópolis, constata-se a relevância da realização do mesmo, utilizando como exemplo o evento esportivo Iron Man, ocorrido em período paralelo ao da realização da pesquisa. O evento anteriormente citado apresenta um grande potencial de atração de estrangeiros e, consequentemente o incremento de recursos financeiros na economia regional derivados dos gastos

A questão da opção de entretenimento utilizada por aqueles que vêm a eventos remete a uma problemática e a uma oportunidade, no que tange ao aproveitamento deste nicho de mercado.

É importante destacar que, o clima foi citado como importante fator de atratividade na baixa estação, notadamente, por segmentos que buscam as praias da Ilha de Santa Catarina Florianópolis - como espaço de lazer, descanso e entretenimento. Este fato remete a constatação da necessidade da adequação dos elementos da oferta relacionados a esta base de atrativos, de modo a ampliar a captação dos fluxos e estender a permanência dos mesmos no Espaço.

De outra parte, a constatação do atrelamento da imagem do destino à base de recursos naturais - praia - requer o esforço articulado à sua desvinculação, bem como, a inserção de elementos da paisagem histórico-cultural, de modo a maximizar a atratividade do local para períodos de baixa temporada.

O transporte no município deve ser aprimorado bem como as estradas, rodovias e vias de acesso que o integram.

Os estabelecimentos comerciais, em geral, devem tomar atenção à questão idiomática seja no atendimento falado ou escrito, particularmente, no que tange ao domínio do Inglês como segundo idioma, sob pena de perda de clientes. 
A oferta de entretenimento deve ser ampliada, conforme citado anteriormente, podendo basear-se em aspectos culturais, ecoturismo, ofertando serviços para a terceira idade, não havendo restrição de serviços em períodos de baixa temporada, com o aprimoramento da infra-estrutura e a atratividade geral das opções de entretenimento disponíveis.

Analisando o perfil do turista em visitação a Florianópolis constatou-se que o mesmo apresenta idade média de 40 anos, renda mensal média elevada, nível de escolaridade superior e a maioria é de solteiros. Torna-se, portanto, necessário compreender esse contexto para a adequação do produto turístico.

\section{Conclusão}

Dentre as conclusões do estudo, algumas merecem destaque.

A atividade turística em Florianópolis está estruturada, basicamente, para a recepção de fluxos turísticos do MERCOSUL, notadamente Argentinos, Paraguaios e Uruguaios, seja com relação a oferta de capital humano habilitado à conversação no idioma do visitante ou no que diz respeito a operação de serviços de hospedagem e alimentação estruturados para a operação durante a estação verão.

A consolidação diante dos mercados de uma imagem fundamentada no conceito de "sol e mar” fragiliza o destino, na medida em que limita o período de demanda, particularmente em territórios sujeitos a alterações climáticas que impedem o uso deste espaço de lazer durante as quatro estações do ano.

No contraponto deste quadro de fragilidade, surge como opção a diversificação dos componentes da oferta, inclusive, através de um processo de especialização produtiva, o qual pode ser atingido através da diversificação e da qualificação dos componentes da oferta para atendimento de segmentos especializados, independente das estações climáticas.

A análise dos dados da pesquisa empreendida possibilitou a sistematização de algumas constatações seja com relação aos componentes da infra-estrutura de equipamentos de consumo coletivos- públicos ou privados - ou quanto aos serviços regulares colocados à disposição dos usuários. 
As deficiências identificadas remetem à necessidade de ajustes da oferta de modo, a possibilitar a maior competitividade do destino, particularmente, no processo de captação e atratividade de fluxos turísticos estrangeiros originários de países distintos daqueles que integram o MERCOSUL.

Os ajustes que se fazem necessário à adequação da oferta passam pela reestruturação de equipamentos de hospedagem, alimentação, entretenimento e lazer, transportes coletivos, sistemas de informações turísticas, além da ampliação de pontos de operação ATM, de modo a possibilitar maior conforto e segurança aos visitantes.

Ainda em convergência com a busca de maior grau de competitividade do destino, a sua integração aos municípios vizinhos e a reestruturação da oferta, a partir da concepção e operação de roteiros turísticos integrados temáticos é alternativa à diversificação, qualificação e especialização produtiva para inserção no mercado internacional e manutenção de fluxo regular ao território.

Com o mesmo intuito, - a redução de custos promocionais - acredita-se que a realização de campanhas promocionais, a partir do Rio de janeiro seria uma opção com potencial de atração de públicos estrangeiros de diferentes nacionalidades e pré-disposição para a visitação. Tal constatação é fundamentada em aspectos como distância geográfica e temporal, estrutura de custos - se comparada a necessidade de promoção no ponto de origem do turista - e a intenção de viajar - uma vez que esse turista já realizou o primeiro e, provavelmente, mais longo deslocamento.

Analisando o potencial da Internet, como fonte de informação mais utilizada pelos entrevistados, constata-se a necessidade urgente, de adaptação do conteúdo das páginas relacionadas ao turismo do município. A questão idiomática, ou seja, o fato de poucas páginas possuírem versões em idiomas diferentes do português - inclusive aquelas de órgãos municipais -, mostra-se como um entrave ao desenvolvimento da atividade turística internacional. Portanto, faz-se necessária a adequação, ao menos, aos idiomas inglês e espanhol, tendo em vista a influência desses como primeiro idioma da maioria dos estrangeiros que visitam o município.

Por fim, cabe ressaltar que foram constatadas uma série de divergências, entre os dados obtidos na realização desta pesquisa, e os dados fornecidos pela Pesquisa Mercadológica de Estudo da Demanda Turística - realizada pela SANTUR em parceria com a prefeitura do 
município. Os dados divergem em aspectos relacionados aos gastos diários realizados pelo turista, principais mercados emissores, meios de hospedagem mais utilizados, principalmente. Recomenda-se a realização de análise comparativa vertical, com o objetivo de avaliar a metodologia que apresenta maior grau de aderência ao processo de identificação e análise das demandas dos consumidores - turistas, através de um estudo longitudinal empreendido ao longo do ano de maneira regular.

\section{Referências Bibliográficas}

BABBIE, E. 1989. The practice of social research. California: Wadsworth Publishing Company.

BARBETTA, Pedro Antonio Alberto. 1999. Estatística aplicada às ciências sociais. Florianópolis Ed. da UFSC.

BARDIN, Laurence. 1977. Análise de Conteúdo. São Paulo: Edições 70.

BENI, Mario Carlos. 2003. Análise estrutural do turismo. São Paulo: SENAC.

BERTALANFFY, Ludwig von. 1973. Teoria geral dos sistemas. Petrópolis: Vozes.

BOULLÓN, Roberto. 1985. Planejamento Turístico. México: Trillas.

CHURCHILL, G. A. 1991. Marketing Research methodological foundations. Forth Worth The Dryden Press.

COBRA, Marcos. 2001. Estratégia de marketing em serviços. São Paulo: Cobra.

ENGEL, James F., BLACKWELL, Roger D., MINIARD, Paul W. 2000. Comportamento do Consumidor. Ed. 8. Rio de Janeiro: LTC.

FIGUEROLA PALOMO, Manuel. 1985. Teoria econômica del turismo.Madrid Alianza Editorial.

GORDON, Ian H. 2004. De Olho na Concorrência. São Paulo: Futura.

KERLINGER, F. N. 1980. Metodologia da pesquisa em ciências sociais. São Paulo: EDUSP.

KOTLER, Philip. 1994. Marketing Público: como atrair investimentos, empresas e turismo para cidades, regiões, estados e países. São Paulo: Makron Books.

; BOWEN, John; MAKENS, James. 1997(b). Mercadotecnia para hotelería y turismo. Mexico: Prentice Hall Hispano america S.A.

2002. Marketing de Serviços Profissionais: estratégias para impulsionar sua atividade, sua imagem e seus lucros. Barueri: Marole.

2003. Princípios de Marketing/ Philip Kotler, Gary Armstrong; tradução Arlete Simile Marques, Sabrina Cairo; revisão técnica Dilson Gabriel dos Santos, Francisco J.S.M. Alvarez.-9 ed. São Paulo: Prentice Hall. 
OMT. Statistics. S/D. Disponível em: http://www.unwto.org/statistics/basic_references/index-en.htm.

PETROCCHI, Mario. 2001. Gestão de Pólos Turísticos. São Paulo: Futura.

PINE, J.; GILMORE, J. 1999. O espetáculo dos negócios: desperte emoções que seduzam os clientes, sensações intensas determinam o valor de produtos e serviços. Rio de Janeiro: Campus.

RICHARDSON, R. J. et al. 1985. Pesquisa social: métodos e técnicas. São Paulo: Atlas.

SÁ, Rosana Bignami Viana de. 2002. A imagem do Brasil no Turismo: construção, desafios e vantagem competitiva. São Paulo: Aleph.

SANTUR, Pesquisa mercadológica da demanda turística. 2005. Disponível em: http://www.sol.sc.gov.br/santur/FrameMunicipios.asp. Acesso em: mai. 2006.

SELLTIZ, C. et al. 1987. Métodos de pesquisa nas relações sociais. 2 ed. São Paulo: EPU.

SWARBROOKE, John. et al. 2002. O Comportamento do Consumidor no Turismo. São Paulo: Aleph.

TRIGO, Luiz Gonzaga Godoi. 1996. Turismo e qualidade: tendências contemporâneas. 2ed. Campinas, SP: Papirus.

Recebido em: 14/02/2007 (1 ${ }^{\text {a }}$ versão) $16 / 03 / 2007$ ( $2^{\mathrm{a}}$ versão)

Aprovado em: 30/06/2007 